\title{
chę
}

\section{Estado, políticas públicas e segurança no Pronasci: ascensão e queda}

\section{Lucia Maria Bertini}

Mestra em Planejamento e Políticas Públicas - UECE

\section{Francisco Horácio da Silva Frota}

Doutor em Sociologia pela Universidade de Salamanca

Professor do Programa de Pós-Graduação em Políticas Públicas (PPGPP) da

UECE

\section{Resumo}

Este artigo analisa o Programa Nacional de Segurança com Cidadania (Pronasci) como política de segurança pública no Brasil, a partir de revisão da literatura pertinente e apontamentos sobre a vivência da execução municipal do Pronasci em Fortaleza/CE. O estudo recupera o caminho das políticas públicas de segurança no Brasil, situando-as no contexto político pós-ditadura militar. Avalia-se a proposta de segurança pública com cidadania do programa estudado, com vistas a superar um modo de controle social mantido por meio de práticas repressivas, tradicionais e pouco efetivas, herdadas de um regime autoritário, examinando sua execução em uma metrópole do Nordeste brasileiro, onde não teve fôlego para se estabelecer como política alternativa, tampouco para reduzir a violência.

Palavras-chave políticas públicas; segurança pública; ditadura militar; cidadania.

\begin{abstract}
This article analyzes the Brazilian National Program of Public Security with Citizenship (PRONASCI) as a public security policy in Brazil, based on literature review and notes on the experience of municipal execution of the PRONASCI in Fortaleza, Ceará, Brazil. The study resumes the path of public security policies in Brazil, placing them in the political context post-military dictatorship. The public security proposal with citizenship of the program under analysis is evaluated, with a view to overcoming a mode of social control maintained through repressive, traditional, and ineffective practices, inherited from an authoritarian regime, examining its execution in a metropolis of Northeastern Brazil, where it did not have the strength to establish itself as an alternative policy, nor to reduce violence.
\end{abstract}

Key words public policy; public security; military dictatorship; citizenship.

Conhecer: debate entre o público e o privado

2018, Vol. 08, no 20

ISSN 2238-0426

DOI: 10.32335/2238-0426.2018.8.20.1050

Licença Creative Commons Atribuição 


\section{Introdução}

A partir de revisão da literatura pertinente e de apontamentos sobre a vivência da execução municipal do Programa Nacional de Segurança com Cidadania (Pronasci), este artigo analisa o Pronasci como política de segurança pública no Brasil e propõe reflexões sobre suas diretrizes, as publicações sobre o tema e a prática observada no Ceará - mais especificamente em Fortaleza.

Foram adotadas as seguintes questões de pesquisa:

- O Pronasci é considerado uma política de segurança? Por quê?

- O Pronasci se apresenta como um marco na concepção da política de segurança?

- Por que o Pronasci foi descontinuado?

Ao considerar os fatores que interferem na existência e na forma de estar das pessoas em uma cidade, entende-se que, muitas vezes, a segurança pública acaba reproduzindo a violência, na medida em que se vê a repressão como única via para a resolução de conflitos. Ou, inversamente, busca-se transformar a realidade a partir da compreensão da necessidade de proporcionar melhores condições de vida, saúde e trabalho nos locais que apresentam problemas, possibilitando que a construção da proteção ocorra a partir da própria comunidade.

Analisar o sucesso de uma política pública de segurança é um desafio, pois, muitas vezes, tal iniciativa envolve elementos desconcertantes que nos desafiam a evoluir:

\footnotetext{
Em todo o mundo, entre os especialistas e gestores, estudiosos e profissionais que atuam na área, essa é uma questão controversa. As polêmicas se sucedem em seminários internacionais e visitas de consultores. É simples entender: determinada política pode ser virtuosa e, ainda assim, os indicadores selecionados podem apontar crescimento dos problemas identificados como prioritários - por exemplo, taxas de certos tipos de criminalidade. O contrário também é verossímil: podem conviver uma política inadequada e bons resultados (Soares, 2007, p. 77).
}

A história possibilita compreender o andamento das políticas públicas e traz elementos vividos, que permitem comparar os tempos, observar avanços e retrocessos e formular criticamente os novos tempos. Assim, retoma-se a trajetória da política de segurança no período democrático, examinando a herança da ditadura e os percalços para o avanço em direção de uma política de segurança cidadã.

Com a conquista dos mandatos populares e a assunção do governo Lula, observou-se dificuldade para estabelecer um caminho da segurança pela esquerda, apesar dos avanços concretos em diversas áreas fundamentais, como a redução da fome e da miséria, em um grande esforço de inclusão. Nesse sentido, procuramos as vozes do possível para a 
Política Nacional de Segurança Pública, considerando as marcas que a história já deixou, a realidade que temos vivenciado, os temores que por vezes se avizinham e as esperanças que sempre se renovam quando se alimenta algum sonho, particularmente na perspectiva da redução da violência.

Tendo vivenciado a implantação do Pronasci no país, particularmente em Fortaleza, questionamos seu desuso precoce, já que estava previsto em lei se estender ao menos até o ano de 2012. Praticamente descontinuado no ano de 2011, o programa funcionou até o final do governo Lula, no ano de 2010, sendo gradativamente desativado como política majoritária já no primeiro mandato do governo Dilma (2011-2014), apesar de fortalecido na primeira Conferência Nacional de Segurança Pública, em agosto de 2009.

O Pronasci trouxe à prática uma proposição de segurança pública com cidadania que tinha como condição, para poder ser efetiva, a superação do conceito da responsabilidade somente das polícias ou de um governo estadual, também abarcando as direções, os interesses federativos e os definidos pela sociedade civil. Nesse contexto, diversos entusiastas, estudiosos, pesquisadores e trabalhadores sociais estavam convictos na integração entre sociedade civil, entidades e comunidade, a qual seria responsável por um conjunto de políticas sociais desenvolvidas na rede de atenção social envolvendo prefeituras, governos estaduais e governo federal, além de seus trabalhadores, agentes de segurança, de saúde e de assistência social. Uma metodologia que possibilitaria a agentes, técnicos e operacionais desencadear mudanças para avançar na garantia dos direitos, qualificar as forças coercitivas e, finalmente, reduzir a violência.

\section{Políticas públicas para a manutenção ou para a transformação: o PRONSASCl é considerado uma política pública?}

A elaboração de uma política pública decorre de um processo político no qual se encontram em disputa as diversas concepções do problema e o modelo a ser implementado, oriundos de uma demanda complexa e contando com apoios internos e da própria sociedade, e é nesse processo que se obtém a resolução pacífica, mas principalmente revestida de um caráter público, ou seja, imperativo, pois envolve estratégias e ações a partir de decisões dotadas de autoridade desse Poder Público. A demanda referida provém de atores políticos, públicos ou privados, instituições, atores individuais ou coletivos, que alternam seu poder e influenciam a geração dessas políticas públicas permanentemente, constituindo diferenciadas correlações de forças e incidindo sobre a agenda governamental e política. E, às vezes, pela complexidade que envolve, torna-se um problema a ser administrado: 
[...] quando uma política envolve diferentes níveis de governo - federal, estadual, municipal - ou diferentes regiões de um país, ou, ainda, diferentes setores de atividade, a implementação pode se tornar uma questão problemática, já que o controle do processo se torna mais complexo (Rua, 2009, p. 96).

Desde sua criação, o Pronasci traz a decisão política de mudar uma situação há muito problemática, conflituosa, que levou nosso país a ser um dos campeões em assassinatos e que recebe, ainda, a demanda ansiosa e uma pressão crescente da sociedade civil organizada por mudanças na política pública de segurança. E esse é o debate permanente, pois não basta uma decisão nesse cenário complexo. É preciso disputar, correr riscos, transformar e avaliar.

Assim, pode-se afirmar que a segurança pública é "um campo em disputa [...] empírico e organizacional que estrutura instituições e relações sociais em torno da forma como o Estado administra ordem e conflitos sociais" (Costa \& Lima, 2014, p. 482). Nesse caso, formado "por diversas organizações que atuam direta ou indiretamente na busca de soluções para problemas relacionados à manutenção da ordem pública, controle da criminalidade e prevenção da violência" (Costa \& Lima, 2014, p. 482). Essa visão sistêmica envolvendo uma articulação federativa entre União, estados e municípios é recente e ainda se mostra pouco efetiva. É de 2014 o Pacto Federativo para a segurança Pública, estabelecido para garantir a Copa do Mundo, através da Operação Brasil Integrado (BRASIL, 2014), mas desde a Constituição de 1988 este debate se faz presente. Da mesma forma, a participação da sociedade civil se imbrica nessa perspectiva de campo, mas ainda se mostra incipiente, inserida gradualmente na medida em que a segurança pública e a redução da violência se tornam pautas das agendas nacionais na década de 1990 (Souza, 2015). Antes disso, as corporações policiais eram as responsáveis pelo controle da lei e da ordem em um sistema de Justiça Criminal de ação coercitiva e reativa à violência, em uma lógica baseada no tripé polícia-justiça-prisão (Gonçalves, 2009 como citado em Souza, 2015). Combina-se a esse fato o conceito de segurança pública no Brasil, associado à segurança nacional, herança de um passado recente de ditadura militar em que o uso da força e a repressão se colocavam como práticas supostamente necessárias diante de ameaças externas.

Existem muitas referências ao fato de que foi somente a partir da Constituição Federal de 1988 (CF/1988)' que se expressou mais efetivamente um movimento pela garantia de direitos e foram estabelecidos novos paradigmas democráticos. Foi também nessa Carta Magna que apareceu um inédito capítulo sobre segurança pública, mesmo que resgatando a previsão de 1937 - artigo 16, inciso V -, mas sem assumir a atividade por nenhuma instituição

1 A Carta Magna de 1988 é considerada a Constituição Cidadã. Promulgada em 05/10/1988 e resultante de processo constituinte próprio, simboliza o maior período democrático brasileiro desde 1946. A Assembleia Nacional Constituinte, 
até 1988 (Costa \& Lima, 2014). Mesmo assim, não há especificação de conceito ou definição na CF/1988, mas indicação das instituições que dela fariam parte, ampliando os problemas de autoria e criando zonas de atrito, já que introduziu, por exemplo, os municípios como responsáveis por formular e executar políticas preventivas e de combate à violência, além de manter o modelo de organização policial segmentado entre polícia civil e polícia militar (Costa \& Lima, 2014).

Desse modo, a análise da construção da política de segurança na CF/1988 aponta muitos elementos controversos, confirmando o jogo de interesses e mesmo a disputa entre o avanço e o retrocesso nas políticas públicas que se seguiu a ela. O que de fato se coloca são diversos aspectos a ser superados diante de uma insistência da ditadura militar permanecer em vigor com seus métodos, apesar dos ventos democratizantes, por um lado, e da força dos movimentos para que se cumpram as definições da chamada Constituição Cidadã, e dos avanços da democracia, por outro.

\section{Ditadura renitente e mobilização da sociedade civil}

O Brasil apresenta um histórico em que as ações de segurança pública ficaram restritas ao processo de contenção social característico do período da ditadura militar e, mesmo com sua superação, traduzida na democratização do país, reapresentaram-se as velhas práticas, repetindo-se as mesmas decisões que já eram tomadas antes e mantendo-se um "sistema altamente insulado, centralizador e autoritário" do período ditatorial. Esse sistema compõe um círculo vicioso que compreende a necessidade de um controle rígido da ordem cada vez maior, na medida em que a violação das normas é percebida como sistemática desde um grupo identificado como responsável pelas mazelas e problemas que temos das classes perigosas aos pobres e miseráveis - e a tal violação deve corresponder mais controle e novas punições. Tudo isso sustentado em uma concepção equivocada de lei e ordem que, em sua prática, justifica a arbitrariedade do Estado, que traz a concepção herdada da ditadura militar.

As deficiências no aparato de segurança pública brasileiro prejudicam o exercício da cidadania de milhões de brasileiros. Portanto, demandas por mudanças na política se constituem como [imperativo] ético, moral e formal para a consolidação da democracia em nosso país (Souza, 2015, p. 40).

instalada em 1987 e presidida por Ulisses Guimarães, foi composta por 594 parlamentares, oriundos da Câmara Federal e do Senado Federal, e consistiu em debates em Plenário, nas Comissões e Subcomissões Temáticas. 
A análise da transição nos coloca o próprio paradoxo da constituição de nossa frágil democracia. Ocorreu uma mudança conceitual nos direitos humanos no início dos anos 1980, quando a defesa dos presos comuns foi encampada pelos movimentos que protagonizavam até pouco antes a defesa dos presos e desaparecidos políticos. Ao mesmo tempo que realizavam uma campanha pelos direitos humanos desses presos comuns, no centro do país, o Governo do Estado de São Paulo divulgou inéditos e altos índices de criminalidade, os maiores desde 1964, associando imediatamente o resultado ao desenvolvimento da democracia, com amplo apoio da mídia. O prestígio dos grupos sociais que lutavam anteriormente pela democracia, emprestado às pessoas presas, sofreu um revés, despertando em seu lugar sentimentos de rechaço à defesa dos direitos humanos conhecidos até hoje, quando os defensores de direitos foram chamados de defensores de bandidos, e quando cresceu o apoio às formas violentas de combate e prevenção ao crime. O fomento a um diagnóstico de "desordem social" acabou justificando o alijamento da condição humana aos criminosos, o tratamento de muitas mazelas sociais da população pobre como problema de polícia e de segurança, o aumento gradativo da violência policial, a ação de grupos de extermínio e até a impunidade ao assassinato de camponeses ${ }^{2}$ e trabalhadores urbanos - "para além da segurança, o trabalho policial revela sua faceta de controle armado dos movimentos sociais" (Letizia, 2013, p. 3).

Assim, o que se cria é uma aversão ainda maior às ações de proteção dos direitos das pessoas presas, justificando-se as atrocidades e alimentando uma falsa associação da democracia com a defesa de direitos indevidos:

\begin{abstract}
Desenvolve-se um "embate ideológico" contra os "direitos humanos", que, negando a humanidade dos criminosos, caracterizava o esforço de humanização dos presídios como "privilégio" e vinculava essa política democrática ao aumento da criminalidade. Fato é que ao lado da "redemocratização" do país, crescem de forma bastante acelerada os casos de abusos policiais, culminando no massacre do Carandiru (02/10/1992), com o assassinato de 111 presos comuns. Será que a vinculação da luta pelos direitos humanos aos presos comuns trouxe uma dissociação entre "direitos em geral" e "direitos humanos", com o paulatino crescimento do apoio às formas violentas (públicas e/ou privadas) de combate e prevenção ao crime? (Letizia, 2013, p. 2).
\end{abstract}

Ocorreu uma polarização decorrente de nosso período autoritário, em que o movimento social se colocava em contraposição ao sistema institucional, a partir de sua

2 De 1964 a 1993 ocorreram 1.787 assassinatos de camponeses, com apenas 14 condenações, segundo o Centro de Estudos do Movimento Operário Mário Pedrosa (Cemap). 
espontaneidade e independência das elites e dos partidos, estando o Estado posto como "inimigo autoritário contra o qual se mobiliza a Sociedade Civil". Reativos contra a violência institucional imputada pelo Estado na década de 1970, que afetava principalmente os moradores das periferias, aos poucos, com o papel do Estado na garantia das políticas sociais, respondendo às demandas dos movimentos e realizando melhorias no sistema de serviços, tais relações se amenizaram. No entanto, a seguir, na década de 1980, por conta da crise econômica, a incapacidade do Estado dar respostas às crescentes demandas sociais levou a novas manifestações, dessa vez com ocupação de terras, saques, depredação de ônibus, entre outros (Jacobi, 1987, p. 11).

A ideia de um inimigo comum externo a ser destruído se encontra nos alicerces dessa doutrina, que continua a ser orientadora de comandos militares que agem como se na guerra estivessem. Há que se tratar das práticas que vemos ou ouvimos todos os dias e dos paradigmas que ainda hoje embasam o trabalho de policiais militares e civis e da própria Justiça.

Ampliou-se o campo da ostensividade, das polícias e das medidas judiciais que deram tratamento aos crimes e incidiram sobre a violência em nossa sociedade. A violência perpetrada pelo Estado tem sido objeto de inúmeros estudos e preocupação permanente das instâncias de direitos humanos no Brasil, na América Latina e no mundo. $E$ as funções de proteção e de garantia do Estado passam longe das comunidades - particularmente dos pobres e dos negros (Zaluar \& Alvito, 2006).

\section{Responsabilidade na política pública: o PRONASCI se apresenta como um marco na concepção da política de segurança?}

Analisando as políticas públicas de segurança e Justiça Criminal nas últimas quatro décadas, observa-se um quadro de atraso técnico e de aumento da violência e da criminalidade, em que a sociedade se mantém amedrontada e o controle social se dá por meio de práticas tradicionais e pouco efetivas, ainda herdadas de um regime autoritário (Adorno, 2008).

A criminologia crítica ${ }^{3}$ traz a compreensão de que a doutrina de segurança nacional explica a lógica belicista adotada pela polícia e indica a necessidade de revisão do que

3 A criminologia crítica é uma escola criminológica moderna que confronta as aquisições das teorias sociológicas sobre crime e controle social com os princípios da ideologia e da defesa social. Apresenta uma mudança de foco do autor de crime para o contexto social no qual ele se insere, analisando as relações de poder de ordem macro e microssocial e o estigma, a reação social e a criminalização anterior e posterior ao delito, rejeitando o princípio do bem e do mal e a função reeducativa da pena. 
poderia ser a efetiva função do sistema de Justiça Criminal, de assegurar direitos e garantias fundamentais. Também deixa claro que tal concepção serve para esconder e reprimir uma enorme população pobre que, desse modo, mantém-se sob controle, é criminalizada e destituída de valor social.

Wacquant (1999) explica a prática reiterada da violência pela polícia como uma tradição secular de controle dos miseráveis pela força, cuja origem se encontra na própria escravidão e em conflitos agrários, fortalecida por um longo período de ditadura militar, em que a repressão dos rebeldes se disfarçou como repressão dos delinquentes, confundindo-se a manutenção da ordem de uma elite com a manutenção da ordem pública.

\begin{abstract}
A despeito do retorno à democracia constitucional, o Brasil nem sempre construiu um Estado de direito digno do nome. As duas décadas de ditadura militar continuam a pesar bastante tanto sobre o funcionamento do Estado como sobre as mentalidades coletivas, o que faz com que o conjunto das classes sociais tendam a identificar a defesa dos direitos do homem com a tolerância à bandidagem. De maneira que, além da marginalidade urbana, a violência no Brasil encontra uma segunda raiz em uma cultura política que permanece profundamente marcada pelo selo do autoritarismo (Wacquant, 1999, p. 3, grifo nosso).
\end{abstract}

O quadro recente da ditadura militar fez com que a discussão necessária sobre a segurança nacional para a segurança pública tivesse pouco fôlego, somando-se às características de emergência e politização do tema da segurança, que seguiram caracterizando ações pouco efetivas e nenhum planejamento para as transformações necessárias, mantendo-se as práticas tradicionais e eventuais ações de impacto mais pelo espetáculo do que pela revisão de qualquer modelo.

\footnotetext{
O debate sobre segurança pública é reduzido, mesmo após 1988, quase que exclusivamente ao debate legal e normativo, abrindo margens para a emergência da chamada "legislação do pânico", toda vez que uma tragédia ganha manchetes das mídias impressa e eletrônica (Lei de Crimes Hediondos etc.). Na tentativa de aplacar as pressões da população, leis nem sempre coerentes, e quase sempre supressoras de direitos e com a marca do rigor penal, tornam ainda mais complexo o funcionamento do sistema de [J]ustiça [C]riminal brasileiro, e as políticas de segurança pública ficam como que num pêndulo entre os tempos de gestão e os tempos políticos, quase sempre inviabilizando processos de médio e longo prazos. A atribuição de responsabilidades e o monitoramento das políticas públicas se diluem num rol de múltiplas esferas de poder e de governo, cabendo às polícias o papel de vidraça da ineficiência de um sistema bem mais amplo (Proglhof, 2013, p. 34).
} 
Apesar de a CF/1988 se apresentar como marco referencial para o desenvolvimento de uma ampliação pelo direito e políticas sociais, direção pretendida pelo Pronasci, muitas dificuldades ainda foram apontadas na política de segurança no Brasil, motivo pelo qual se resgata esses elementos históricos que ajudam a entender como se desenvolveu esse processo de transição e como acaba se estruturando com vagar a política brasileira de segurança pública, repercutindo em toda a história subsequente.

\begin{abstract}
É fato que o Estado democrático vem tomando diversas medidas na área de segurança pública, fundamentalmente a partir da Constituição de 1988. Porém, as leis e políticas resultam insuficientes, quando não equivocadas, na medida em que se mantêm intactas regras e práticas institucionais que respondem à lógica do período ditatorial. Os debates ocorridos na ANC resultaram em importantes aspectos de continuidade que permanecem como marcas da atuação das instituições de segurança pública ao longo dos últimos 20 anos, e cujas perspectivas de superação não são muito animadoras - apesar da existência de algumas possibilidades em prol de uma reconfiguração da atuação da polícia em busca de mais eficiência e respeito ao Estado democrático de direito (Instituto de Pesquisa Econômica Aplicada [Ipea], 2009, p. 12).
\end{abstract}

As atribuições constitucionais dos diversos órgãos no sistema federativo, em um país continental como o nosso, para a consolidação da segurança pública, constituem capítulo importante para a compreensão de seu desenho e desempenho institucional e, da mesma forma, para compreender as dificuldades que a instalação de uma política de segurança cidadã ${ }^{4}$ pode apresentar. Sabe-se que a CF/1988 adotou princípios de descentralização, tendo por base a necessária superação do centralismo dos governos ditatoriais. No entanto, isso aumentou a complexidade da política de segurança pública, criando uma espécie de "colcha de retalhos" (Souza, 2015, p. 84) com diversas indefinições tanto no campo operacional quanto no campo estrutural, permeadas pelas diferenças entre interesses territoriais, manutenção do recorte das polícias estaduais entre civil e militar, com políticas de segurança independentes e variando entre estados da federação e o papel central das municipalidades, gerando um arranjo institucional complexo.

A observação da trajetória das políticas de segurança pública demonstra, até os primeiros governos democráticos, a reprodução dos princípios da segurança nacional, da

4 A segurança cidadã é um conceito de segurança preventiva, baseada em um planejamento estratégico proposto formalmente pelo Programa das Nações Unidas para o Desenvolvimento (PNUD), em 1998, a partir dos sistemas internacionais de direitos humanos, para superar desigualdades e reafirmar o Estado democrático de direito, com foco central na proteção da pessoa humana, voltado a interesses comuns, efetivados à luz dos direitos humanos, na perspectiva de um paradigma emancipatório, com vistas a assegurar o livre exercício dos direitos individuais e coletivos de todos os indivíduos membros da sociedade (baseado na ata da Primeira Reunião em Matéria de Segurança Pública nas Américas, realizada em 7 e 8 de outubro de 2008 na Cidade do México). 
parte do Governo Federal, com o combate pontual à criminalidade e a responsabilização integral dos estados. Em seguida, começam a aparecer movimentos em tese e desenvolvimento de projetos e proposições federais com olhares para a realidade e 0 contexto de aumento da criminalidade, esboçando-se planos nacionais de segurança e vislumbrando-se uma tímida tentativa de encampar o debate pelo Governo Federal.

Segundo Soares (2006), analisando o campo da segurança pública no âmbito federal, mesmo após a CF/1988 houve a continuidade de práticas tradicionais, marcadas por "indiferença e imobilismo", conservando-se também os rumos estaduais, com polícias divididas e com total autonomia, sob pequenas adaptações ao contexto democrático, que pouco significaram para uma efetiva mudança diante do legado de práticas autoritárias mantidas:

\footnotetext{
As autoridades que se sucederam [ao processo constitucional] limitaram-se a recepcionar o legado de nossa tradição autoritária, acriticamente, reproduzindo suas características básicas, introduzindo meros ajustes residuais. Ou seja, as polícias e suas práticas deixaram de ser, ostensivamente, voltadas com exclusividade para a segurança do Estado, redirecionando-se, no perfunctório, para a defesa dos cidadãos e a proteção de seus direitos - sobretudo [n]o nível do discurso oficial e dos procedimentos adotados nas áreas afluentes das cidades (Soares, 2007, p. 86).
}

Não é possível falar em uma política de segurança até meados da década de 1990, tampouco identificar a segurança pública compondo o rol dos direitos de cidadania, associando-se essa realidade às origens de nosso sistema penal, sobre os mecanismos de controle da ordem, não tratando da mesma forma diferentes segmentos sociais, mas ao contrário, oferecendo "proteção e garantia de direitos para uns e punição (às vezes demasiado severas) para outros" (Souza, 2015, p. 63).

Assim, estas diferenças caracterizavam o tema, direcionado aos interesses políticos e econômicos:

O que existia era um sistema de segurança estatal não público, a serviço de determinadas classes e interesses (políticos e econômicos), montado para a proteção patrimonial dos segmentos abastados e cuja burocracia, essencialmente militarizada, respondia às demandas das elites nacionais (Souza, 2015, p. 62).

O fato de que a ditadura militar tenha terminado não traduz automaticamente a passagem para um período de franca democracia. Tampouco a Constituição Cidadã garante 
essa passagem. Pinheiro (1997, p. 47) explica a concepção de O’Donnel sobre a existência de períodos de transição, que constituem objeto de atenção às práticas autoritárias, heranças e garantias de grupos de interesse e elites que se mantêm:

\footnotetext{
Guilhermo O’Donnel refere-se a essa passagem como a "primeira transição" - sair de um regime autoritário para um governo eleito - e a "segunda transição" como a institucionalização das práticas democráticas em todos os níveis do Estado. Em muitos países [pós-ditadura] que não têm uma longa tradição democrática, a "segunda transição" ficou imobilizada por inúmeros legados do passado autoritário.
}

As explicações de uma forte herança militarista e de poucas palavras, com foco na proteção do patrimônio e na desconfiança sobre as pessoas, aqui discorridos, trazem-nos à atualidade desse momento de "segunda transição" e a clareza sobre os longos passos a ser trilhados por toda política que queira estabelecer novos patamares de respeito e de proteção de direitos, como aquela proposta pelo Governo Federal ao apresentar o Pronasci.

Observa-se, na história, que a mudança de paradigmas e a alteração dos processos tradicionais de segurança não são automáticas. A possibilidade de construir o Estado Necessário começa por forte vontade política, passa pela capacitação de quadros técnicopolíticos, integrando o conhecimento técnico, formal e o conhecimento forjado no dia a dia, informal e indutivo. Costa e Dagnino (2014, p. 25) apontam a integração e a conformação de novos enfoques multidisciplinares:

\begin{abstract}
A administração pública, a partir da constatação de que os hiatos entre o produto obtido e o planejado não eram simplesmente um sintoma de [má] administração, mas que poderiam se dever a problemas anteriores à fase de implementação propriamente dita. E a ciência política, a partir da constatação de que a formação da agenda de decisão, já no interior do sistema de elaboração de políticas, em torno da qual se iniciava o processo, e da qual dependia, significativamente, o conteúdo da política, era, em [si], determinada pelas forças políticas que se expressavam no contexto econômico-social que envolvia o sistema. Isto é, que as determinações políticas, econômicas e sociais não eram um simples insumo do processo, mas algo que seguia atuando dentro do sistema ao longo de todo o processo.
\end{abstract}

Finalmente, apareceram os indicadores para a superação do problema na construção de pontes, em pactuações que, se não resolvessem por si a problemática em questão, 
permitiam o avanço na desconstrução do status quo e no estabelecimento de novos patamares de ação. Castro e Oliveira (2014, p. 23) abordam a perspectiva da legitimação da política pública em sociedades contemporâneas a partir da existência de pactuações e do estabelecimento de metas na formulação e implementação, envolvendo a sociedade:

Nas sociedades contemporâneas, cabe ao Estado prover políticas públicas que atendam aos anseios da sociedade. Para que as funções estatais sejam exercidas com legitimidade, é preciso haver planejamento e permanente interação entre governos e sociedade, de forma que sejam pactuados objetivos e metas que orientem a formulação e a implementação das políticas públicas.

As bases para a modificação da tradicional forma de fazer segurança já vinham sendo discutidas antes mesmo da constituinte, já que houve pressões da sociedade civil por mais direitos e menos violência contra as classes populares desde lá. No entanto, todo o arcabouço de leis e estruturas governamentais trazidas nesse período prescindem do vigor da prioridade na política e efetiva transformação, aparecendo ao longo do governo Fernando Henrique Cardoso como projeto e formulação, mas sem força e decisão de mudança efetiva, com o avanço e as transformações necessárias (Adorno, 2008; Soares, 2007). O Pronasci, mais tarde, incorporou uma vez mais os princípios e as prerrogativas ensaiadas no processo de formulação da democracia, traduzindo uma possibilidade de realização diferenciada e, ao mesmo tempo, fazendo-nos rever os problemas e os entraves que impediam o desenvolvimento de uma política de segurança pública cidadã.

Temos um contexto que demanda profundas transformações, envolvendo os principais protagonistas do que temos na política de segurança em nosso país: as forças de segurança, envolvendo as polícias. Saín (2012) se mostra cético quanto à capacidade das polícias se reformarem, já que, conservadoras, não têm interesse em mudanças e apresentam baixa capacidade de análise e identificação da complexidade do contexto. O autor aponta, ainda, a realidade latino-americana, na qual os governos de esquerda também se mostram conservadores. Saín (2012, p. 213) indica o Pronasci como uma tentativa, reformista, mas que perdeu da agenda a reforma das polícias:

Eu diria que Kirshner na Argentina, Lagos e Bachelet no Chile, Lula no Brasil, Tavarè Vasquez e José Mujica no Uruguai foram governos profundamente conservadores no tocante à polícia. Foram governos que governaram a segurança pública com a mesma lógica da direita e que reproduziram o sistema da mesma maneira. Há, por algum momento, algum discurso reformista, alguma política social, como por 
exemplo o Pronasci no Brasil, mas não há ênfase nestes temas e nunca colocaram na agenda as reformas policiais.

Saín (2012) vislumbra a possibilidade de mudança a partir de uma reforma e a "efetiva incidência de mudanças dentro e fora da instituição", somente com articulação política e consenso social, envolvendo a realização de um diagnóstico e o desenvolvimento de um projeto institucional a partir das necessidades e da realidade local, agregando-se capacidade técnica, gestão estratégica, gestão política e gestão organizacional. Tudo isso porque na reforma "serão rompidos negócios ilegais, anuladas vantagens institucionais e alteradas a estrutura de poder e as formas de domínio” (SAÍN, 2012, p. 214).

Nesta análise, exalta-se a importância estratégica da sociedade civil e apresenta-se a perspectiva de superar os tempos da política, pois mudanças estruturais sempre ocupam o tempo para além de um governo. Por fim, abordam-se o crime organizado e suas relações com o status quo, que também explicam, em parte, a incapacidade de mudança, bem como a realidade de setores médios da população que não estão associados ao crime, mas são seus principais consumidores, o que acaba por explicitar um alto grau de conexão das estruturas institucionais, políticas e econômicas com o crime, em uma espécie de "consórcio entre atores criminosos e atores legais" (Saín, 2012, p. 219), a respeito do que a polícia e o Estado não se manifestam, a não ser em alguma crise em que as coisas escapam do controle, necessitando intervir para manter a estabilidade do governo. Nesse caso, não se trata de falta de Estado, pois muitas vezes se diz, pelo contrário, que ele está imbricado com esses mercados informais e ilegais, regulando-os, por meio tanto da polícia quanto de políticos e dos demais atores locais, configurando uma sociabilidade em torno de mercados ilegais de difícil superação.

\section{A arrancada do governo Lula na direção da democracia: pressupostos e diretrizes avançados}

Nesse governo foi possível - sem alterar muito os propósitos anteriormente delineados de cooperação entre estados e federação, de acesso à justiça, de reaparelhamento e reorganização dos órgãos de segurança e de qualificação do sistema penitenciário, formulados no governo Fernando Henrique Cardoso, mas praticados de forma incipiente colocar em prática as promessas do governante anterior, aumentando significativamente a capacidade de execução daqueles propósitos (Adorno, 2008).

Sá e Silva (2012) também aponta maior grau de efetividade nas ações estruturadas pela Secretaria Nacional de Segurança Pública (Senasp) e pelo Fundo Nacional e implementadas no primeiro mandato do Governo Lula (2003-2006), que, em sua estreia, 
já estabeleceu e desempenhou um papel de indução de políticas pelo Governo Federal. Identificou, desde cedo, a necessidade de planejar e incrementar a gestão para uma Política Nacional de Segurança Pública, como demonstraram os esquemas apresentados pela Senasp do Ministério da Justiça à época (Sá e Silva, 2012), envolvendo-se de modo a mudar o perfil da área.

Com vistas a uma gestão estratégica, a Política Nacional de Segurança Pública aponta a necessidade de integração das instituições policiais de modo sistêmico, recomendando a colaboração e a aproximação dos entes federados na gestão da segurança. Isso para garantir a promoção das ações preventivas, superando o modelo repressivo e orientando a ação de acordo com informações monitoradas e geridas conjuntamente. Ao mesmo tempo, o planejamento leva ao estabelecimento de rotinas, funções, processos e estruturas que se tornam ágeis, com vistas a atingir metas, produzindo, por sua vez, dados qualificados para obter um diagnóstico rigoroso; planejando-se sistematicamente e avaliando-se regularmente. Esse processo sistêmico é previsto no Plano Nacional de Segurança Pública e reafirmado na avaliação do final do primeiro mandato, de modo a garantir um ciclo virtuoso da gestão da política, oferecendo o ciclo que vai da reorganização institucional até o controle externo, sempre garantindo a gestão do conhecimento, a valorização e a formação profissional, a modernização da perícia e a prevenção (Ministério da Justiça como citado em Sá e Silva, 2012, p. 39). Esse amplo processo foi traduzido em uma instância integradora nos níveis federal e estaduais, chamada Gabinete de Gestão Integrada (GGI), que constituiria um braço operacional do Sistema Único de Segurança Pública (SUSP), item que chegou a um bom desempenho, como se relata:

\footnotetext{
O GGI seria um fórum executivo que reuniria as polícias de todas as instâncias, e, mediante convite, as demais instituições da Justiça [C]riminal. As decisões seriam tomadas apenas por consenso, para que se eliminasse o principal óbice para a cooperação interinstitucional: a disputa pelo comando. Como se constatou haver ampla agenda consensual para ações práticas na área da Segurança Pública, não se temeu a paralisia pelo veto. Observe-se que os GGI começaram a operar imediatamente, e, nos raros Estados em que, nos anos seguintes, não foram esvaziados pelo boicote político, renderam frutos e demonstraram-se formatos promissores. [...] Assim, em 2003, chegamos a um acordo nacional em torno de transformações significativas e criamos uma nova agência operacional, os GGI, mas os resultados se perderam em decorrência da alteração de rota no Ministério da Justiça e no Planalto (Soares, 2007, p. 88).
}

Nesse período foi criada a rede nacional de estudos e desenvolvimento permanente para a formação dos agentes de segurança, que se denominou Rede de Altos Estudos em Segurança Pública (Renaesp), que teve seu projeto-piloto no ano de 2005. Essa 
definição estruturou de forma bastante consistente a base curricular nacional para os profissionais da segurança, instalada até os dias de hoje. A matriz curricular nacional foi desenvolvida agregando a ela as Diretrizes Pedagógicas para as Atividades Formativas dos Profissionais da Área de Segurança Pública, orientações para o planejamento, acompanhamento e avaliação das ações formativas, e a Malha Curricular, composta das disciplinas com os conteúdos "conceituais, procedimentais e atitudinais" (Brasil, 2009, p. 2) que contribuem para o estabelecimento, a clareza da unidade de pensamento e a ação dos profissionais, conforme a apresentação. Atualizada em 2005 e 2008, trata-se de uma poderosa ferramenta consolidada de referência para toda a formação dos profissionais da segurança pública, independente da instituição, do nível ou da modalidade de ensino em que seja desenvolvida. Significou uma efetiva mudança na condução de linhas mestras para a formação de todos os profissionais da área, inserindo conteúdos primordiais para o avanço na dupla direção de padronizar e estabelecer critérios, ao mesmo tempo buscando a humanização de tal formação e a transversalidade dos direitos humanos.

Também foi criado o SUSP, o qual sintetiza a centralidade da cidadania e dos direitos humanos, a fim de superar o constante antagonismo verificado na história, e lança a estruturação de Áreas Integradas de Segurança - integração local das diversas forças de segurança - para uma melhor leitura do território, além de propor a articulação operacional dos estados por meio de suas polícias. Muitos autores se referem mais como uma tentativa do que uma efetividade (Soares, 2007; Souza, 2015). A observação desse Projeto de Lei $(\mathrm{PL})$ n. 3.461/2008 indicou que ele tramitou, sendo revisado e ampliado, de 2009 a 2015, constando em 2016 como PL n. 3.734/2012, ainda em avaliação na Comissão de Segurança Pública e Combate ao Crime Organizado, que propôs a criação de um Ministério da Segurança Pública, conforme relatório de proposições relacionadas da Câmara dos Deputados ${ }^{5}$.

Avanços foram claramente identificados e logo no primeiro ano sofreram um reordenamento, com a saída do Secretário Nacional. Houve o recuo da gestão federal na proposta radical originalmente trazida pelo Projeto Segurança Pública para o Brasil (2002) no modelo tradicional de política de segurança pública, cujas alterações substanciais, em vários níveis, foram inviabilizadas pela falta de coalizão política para sua implementação, conforme avaliação de Tarso Genro (como citado em Gonçalves, 2009, p. 100), que assumiu o comando do Ministério da Justiça no segundo mandato, propondo a realização da Primeira Conferência Nacional de Segurança Pública, com o objetivo principal de ampliar o "debate sobre a segurança pública envolvendo os atores políticos e sociais que incidem na política”, frisando, no discurso de lançamento dessa conferência a necessidade da confluência de ideias e do consenso ainda não obtido entre os atores da comunidade da política de segurança. Com a clareza desse quadro político se lançou o Pronasci.

5 A esse respeito, ver o parecer do Deputado Artur Bruno, do Ceará, que explicita o teor integral do PL do SUSP, conforme tramitação demonstrada em http://www.camara.gov.br/proposicoesWeb/fichadetramitacao?idProposicao=542102. 


\section{O advento do PRONASCI}

A proposta governamental apresentada em 2007 desenhou um programa de segurança pública para estados e municípios, com base no pacto federativo, que mobilizasse e envolvesse a sociedade civil para se tornar um programa de todos e oferecesse solução para o problema da violência e da criminalidade, com base na necessidade de "integrar políticas públicas sociais com as políticas preventivas de segurança pública [...] e de enfrentar as causas sociais, culturais e econômicas da criminalidade na constituição de uma política de segurança social cidadã" (Brasil, 2010) ${ }^{6}$.

A partir do diagnóstico sobre a situação dos jovens no Brasil, reformularam-se os programas voltados à juventude e, junto à Casa Civil, que passou a ser uma espécie de câmara gestora dos programas sociais do governo para o Pronasci, a gestão ampliou os investimentos em diversas áreas, envolvendo Saúde, Desenvolvimento Social, Cidades e Educação e incrementando e reordenando vários projetos, programas e ações, sempre por meio de debates coletivos, a partir de reuniões que foram "costurando o [Pronasci] nesta grande malha de projetos sociais existentes no Governo Federal" (Fernandes, 2012, p. 24). Ao envolver o Ministério Público e os segmentos sociais, previu a sistematização de dados da Senasp para compreender a situação do país em relação às mortes violentas e seus recortes local, social e etário, configurando, dessa forma, regiões prioritárias para o atendimento e a consolidação do programa (Fernandes, 2012). Dando continuidade à implementação do SUSP, foi por meio do Pronasci que os municípios se envolveram, aperfeiçoando a experiência e constituindo adesão em grande escala, uma vez que já vinham se envolvendo no debate. É do ano da criação do Pronasci - 2007 - o dado de que $22 \%$ dos municípios possuíam estrutura organizacional específica para assuntos relacionados à segurança, como as próprias guardas municipais, conselhos locais participativos e até a gestão da segurança urbana, com destaque para ações relacionadas ao envolvimento da população, das políticas sobre drogas, do desarmamento, da cultura de paz e da governança integrada, contemplando uma demanda que já estava em estruturação. Adorno (2008, p. 41) afirma que o escopo do programa era "articular o enfrentamento da criminalidade com ações sociais, priorizando a prevenção e o tratamento das causas que explicam o crescimento da violência nesta sociedade, sem abrir mão da lei e da ordem".

Com mais de 100 ações - 94 no lançamento e ampliação para 104 nos anos seguintes -, ao longo do primeiro ano se apresentaram propostas que envolviam a União, os estados, os municípios, as organizações sociais e a comunidade, as quais foram sendo cadastradas no sistema de convênios e aprovadas na medida de sua inserção e análise, ainda sem edital prévio. Ao final, configurou-se um conjunto de propostas de Ações Estruturais modernização das instituições de segurança, valorização dos profissionais de segurança

6 Portaria Ministério da Justiça n. 719, de 3 de abril de 2007. 
pública e agentes penitenciários e enfrentamento à corrupção policial e ao crime organizado; e outro conjunto de ações relacionadas a programas locais - Território de Paz; Integração do Jovem e da Família; Segurança e Convivência; Protejo; e Mulheres da Paz ${ }^{7}$-, formando um quadro complexo de inserção que, aos poucos, foi contornando a política nacional e passando a funcionar por meio de editais.

O Pronasci trouxe, em suas principais ações, a atenção e integração do jovem e da família, com foco social e etário; e o território - o município e seus interlocutores e demais atores sociais, na necessária interdisciplinaridade que propõe com a gestão integrada e federativa. O programa inova quando vai até o território, mobiliza a comunidade, alcança melhores condições de vida em espaços mais seguros, identifica jovens que estão em risco social e oferece uma trajetória protegida, pois é preciso observar as ameaças das disputas territoriais e a vulnerabilidade decorrente do enfraquecimento da comunidade nesse contexto; ao mesmo tempo, oferece metodologia diferenciada para o acolhimento e encantamento educacional desse jovem, que muitas vezes é discriminado e negligenciado pelas políticas sociais, preocupando-se com as mulheres, com a violência doméstica e com a comunidade, oferecendo apoio de serviços mais bem qualificados, mediação de conflitos e maior presença dos equipamentos sociais. Cultura, aprendizado sobre os direitos, letramento, mobilização social e apoio psicossocial, trabalho, qualificação, inclusão digital, esporte e lazer fazem parte do cardápio do Protejo e do Mulheres da Paz, entre outros projetos de ampla abrangência trazidos pelo Pronasci ao território.

Tal concepção demonstra que os jovens, em grande escala ${ }^{8}$, não têm oportunidade no Brasil. O trajeto de um jovem pobre é completamente diferente daquele que recebe as condições de desenvolvimento em uma casa acolhedora, bem alimentado e trajado, na escola, letrado, graduado, pós-graduado, com emprego mais acessível. A legião de jovens que não têm acesso a essas condições acaba, muitas vezes, atuando em atividades ilícitas que oferecem alternativa de renda e de status pessoal. Isso sem mencionar o preconceito social frequentemente associado ao risco e à violência.

Faffermann (2006), ao analisar o cotidiano dos jovens trabalhadores do tráfico, aborda essa trajetória sem associar diretamente a pobreza à violência, importante diferenciação a ser observada, mas muito raramente repercutida em nosso cotidiano e menos ainda na mídia. Temos como imaginário social construído a criminalização da pobreza e as formas

\footnotetext{
7 Interdependentes, esses dois projetos estão desde o começo definidos e são a base do Pronasci no Território de Paz: atenção a jovens e mulheres da comunidade. Empoderamento de ambos, apoio comunitário das mulheres, prevenção e combate à violência doméstica e atenção aos jovens em território conflagrado, com acompanhamento das mulheres da comunidade.

8 A taxa de desocupação entre jovens de 18 a 24 anos é crescente no Brasil, sendo caracteristicamente a maior, quando comparada a outros segmentos. No entanto, verifica-se uma verdadeira disparada nessas taxas entre 2014,2015 e 2016: $12,1 \%, 16,8 \%$ e $22,8 \%$, ultrapassando as marcas atingidas até então e alertando os especialistas para uma geração perdida em poucos anos (Cunha, 2016).
} 
ruidosas de tratar os jovens na periferia, "quase pretos de tão pobres" ${ }^{9}$, e justificando nossos métodos truculentos e ostensivos no combate à criminalidade e na reprodução da violência. A realidade se mostra a mais perversa nesse quesito, pois vemos que, para a grande maioria dos jovens, sempre falta a oportunidade e abundam conflitos parentais, miséria e falta de condições para viver dignamente. É preciso enfrentar o paradoxo: como pode um sujeito em condições de constante violação de direitos constituir um projeto de vida e um objeto que dê sentido à vida? Desse não lugar ou lugar de invisibilidade para o submundo do tráfico e das infrações há um curto caminho que pode custar a morte ou o aprisionamento - que, nesse caso, são sinônimos.

Assim, entende-se que o enfoque tradicional da segurança pública criminaliza a pobreza, representando a exclusão dos já excluídos e o aprisionamento de um grande contingente de pessoas que não tiveram sequer acesso aos direitos básicos de saúde, educação e assistência a diversas necessidades, como habitação, lazer e cultura. Grande parte dos altos índices de homicídios em nosso país $(53,5 \%)$ se concentram em jovens entre 15 e 29 anos e, destes, 77\% são negros; menos de $8 \%$ de tais casos chegam a ser julgados (Anistia Internacional, 2014). O genocídio ${ }^{10}$ de jovens tem sido tema das principais instituições de direitos humanos, das entidades de defesa da juventude e da própria Anistia Internacional - Jovem Vivo; Conselho Nacional da Juventude - Juventude Viva; Câmara Federal - Comissão Parlamentar de Inquérito (CPI) de Jovens Negros e Pobres; Organização das Nações Unidas (ONU) - Juventude Negra contra o Racismo e pela Paz; entre outras iniciativas, mas ainda sensibiliza pouco a sociedade em geral, indiferente ao quadro atual, o que só faz aumentar o preconceito e o estereótipo negativo que se associam a esse mesmo jovem e ao seu local de origem. Em um processo de revitimização, se conseguem escapar por um lado, rendem-se pelo outro.

\section{Resultados possíveis e o processo de descontinuidade}

A revisão bibliográfica e o acompanhamento da execução do Pronasci na capital do Ceará (Fortaleza) e nos demais estados, conforme a pesquisa Pensando a Segurança, levada a cabo pelo Núcleo de Pesquisa e Estudos da Universidade Estadual do Ceará (UECE), do qual os autores deste artigo são membros, permitiram observar que as vigorosas ações estruturais não obtiveram o investimento permanente nem sistemático previsto e pouco

\footnotetext{
9 Composição de Caetano Veloso e Gilberto Gil - "Haiti”. Música que enseja o debate das ciências sociais ao denunciar e analisar o preconceito racial, as violações de direitos, a corrupção, o extermínio da população pobre e negra, além das atrocidades identificadas no Haiti, um país do Caribe, e aqui.

10 Genocídio - palavra derivada do grego genos que significa "raça", "tribo" ou "nação", e do termo de raiz latina -cida, que significa "matar", é o extermínio deliberado e sistemático de uma população ou de uma comunidade ou grupo étnico, racial ou religioso, tendo como motivação diferenças étnicas, com vistas à sua extinção. Prática devidamente delimitada pela ONU em 1948, prevê medidas de prevenção e repressão estabelecidas em convenção internacional.
} 
foram associados aos territórios. No Grande Bom Jardim (GBJ)11, apesar da atenção dispensada pelo governo do estado ao Gabinete de Gestão (GGI-M), eram comuns os pedidos de investimento nas polícias locais, de modo a transformar a realidade local para além de algumas obras e parcos investimentos. O GBJ não se transformou efetivamente, do ponto de vista da precariedade da infraestrutura, apesar dos esforços do município associados aos do estado, mas o tamanho do território, em contraponto aos índices de investimento, não permitiu nem mesmo grandes alterações na paisagem. Então, se por um lado tivemos a devida atenção aos jovens, eram poucos os atendidos diante da legião de casos existentes e não houve sequer duas rodadas do Protejo e do Mulheres da Paz no território nem de nenhum de seus diversos projetos, pelo contrário, alguns foram descontinuados antes do término, como o projeto de informatização da comunidade (telecentros). Ao mesmo tempo, altos investimentos em formação também não restaram associados ao território, resultando em uma ação muito mais de apoio e complementação salarial dos profissionais de segurança do que na efetiva transformação da forma de trabalho desses profissionais, que em muito pequena escala12 chegaram a conhecer a proposta global do programa.

Assim, avalia-se que a continuidade e o monitoramento do Pronasci, com as ações previstas, poderiam alcançar patamares diferenciados de melhoria nas relações entre a comunidade e o Estado, transformando a prática policial e obtendo maior apoio dos órgãos de segurança pública, mediante confiança e colaboração. Nem o tempo decorrido ou o investimento realizado, pouco sincronizado para uma ação integrada, chegaram a surtir os efeitos permanentes almejados para a comunidade e seus moradores.

\section{Referências bibliográficas}

Adorno, S. (2008). Políticas públicas de segurança e Justiça Penal. Cadernos Adenauer, 9(4), 9-27.

ANISTIA INTERNACIONAL. Violência: Brasil mata 82 jovens por dia. BRASIL:[s/n] 2014. Campanha publicitária. Disponível em https://anistia.org.br/imprensa/na-midia/violencia-brasil-mata-82-jovens-por-dia/Acesso em 25out 2015.

BRASIL. Constituição da Republica Federativa do Brasil, Brasília, DF: Senado, 1988. Emenda Constitucional: BRASIL.

BRASIL. Lei 11530 - PRONASCI. Diário Oficial da União. Brasília, DF: Ed. 25/10/07.

11 Grande Bom Jardim é a região que envolve os bairros Siqueira, Canindezinho, Granja Lisboa, Granja Portugal e Bom Jardim, na Secretaria Regional V - quinta região administrativa de Fortaleza, e um dos conjuntos de bairros que reuniam maior índice de homicídios na cidade, indicado pelo Observatório da Violência - Fortaleza de Paz, e escolhido pela gestão por este motivo para ser o Território de Paz.

12 Não há números para especificar esse conhecimento, mas efetivamente passaram pela formação do Pronasci 80 guardas municipais. Além daqueles que trabalhavam no território, no máximo 20. 
Brasil. (2009). Matriz Curricular Nacional para Ações Formativas dos Profissionais da Área de Segurança Pública. Brasília, DF: Ministério da Justiça.

BRASIL. Ministério da Justiça. CONSEG - Texto básico. Brasília, DF, 2009.

Brasil. (2010). Experiência: Rede Nacional de Altos Estudos em Segurança Pública (RENAESP). Brasília, DF: Ministério da Justiça.

Castro, J. A., \& Oliveira, M. G. (2014). Políticas públicas e desenvolvimento. In L. M. Madeira (Org.), Avaliação de políticas públicas (pp.20-49). Porto Alegre, RS: Ed. UFRGS.

Costa, A. T., \& Lima, R. S. (2014). Segurança pública. In R. S. Lima, J. L. Ratton, \& R. G. Azevedo (Orgs.), Crime, polícia e Justiça no Brasil (pp.482-490). São Paulo, SP: Contexto.

Costa, G., \& Dagnino, R. (Orgs.). (2014). Gestão estratégica em políticas públicas (2a ed.). Campinas, SP: Alínea.

Cunha, J. (2016, 6 de março). Taxa de desemprego entre pessoas de 18 a 24 anos dispara e ameaça geração. Folha de São Paulo, Mercado. Recuperado de https://www1.folha.uol.com.br/mercado/2016/03/1746926-taxa-de-desemprego-entre-pessoas-de-18-a-24-anos-dispara-e-ameaca-geracao.shtml

Faffermann, M. (2006). Vidas arriscadas: o quotidiano de jovens trabalhadores do tráfico de drogas. Petrópolis, RJ: Vozes.

Fernandes, Caroline Carla Cruz. 0 enfrentamento ao crime através do PRONASCI. Dissertação de Mestrado apresentada à Universidade Cândido Mendes. Pós -Graduação Latu sensu. AVM Faculdade Integrada do Rio de Janeiro, 2012, 48p.

Instituto de Pesquisa Econômica Aplicada. (2009). Brasil em desenvolvimento: Estado, planejamento e políticas públicas - sumário analítico. Brasília, DF: Autor.

Jacobi, P. (1987). Movimentos sociais urbanos numa época de transição: limites e potencialidades. In E. Sader (Org.), Movimentos sociais na transição democrática (pp. 44-65). São Paulo, SP: Cortez. KOPITTKE, Alberto Liebling, ANJOS, Fernanda Alves, OLIVEIRA, Mariana Siqueira de

Letizia, V. (2013). Luta pela revogação da Lei da Anistia em tempos de democracia. São Paulo, SP: [s.n.].

MADEIRA, Ligia Mori (org). Avaliação de Políticas Públicas. Coleção Capacidade Estatal e Democracia. Porto Alegre: UFRGS/CEGOV, 2014.

Pinheiro, P. S. (1997). Violência, crime e sistemas policiais em países de novas democracias. Tempo Social, 9(1), 43-52.

Proglhof, P. N. (2013). (Re)estruturação da segurança pública no Brasil. In Mingardi, G. Política de segurança, os desafios de uma reforma (pp. 145-166). São Paulo, SP: Ed. Fundação Perseu Abramo.

Rua, M. G. (2009). Políticas públicas. Florianópolis, SC: Universidade Federal de Santa Catarina.

Sá e Silva, F. (2012). Nem isto nem aquilo: trajetória e características da Política Nacional de Segu- 
rança Pública (2000-2012). Revista Brasileira de Segurança Pública, 6(2), 412-433.

Saín, M. F. (2012). Gestão da segurança pública na América Latina: campos em diálogo. Marcelo Fabián Saín, entrevistado por Thandara Santos. Revista Brasileira de Segurança Pública, 6(1), 204-220. Soares, L. E. (2006). Segurança tem saída. Rio de Janeiro, RJ: Sextante.

Soares, L. E. (2007). A Política Nacional de Segurança Pública: histórico, dilemas e perspectivas. Estudos Avançados, 21(61), 77-97.

Souza, R. S. R. (2015). Quem comanda a segurança pública no Brasil? Atores, crenças e coalisões que dominam a política nacional de segurança pública. Belo Horizonte, MG: Letramento.

Wacquant, L. (1999). As prisões da miséria. Rio de Janeiro, RJ: Zahar.

Zaluar, A., \& Alvito, M. (2006). Um século de favela (6a ed.). Rio de Janeiro, RJ: Ed. FGV. 